\title{
Roque Dalton hace un llamado a la solidaridad por la vida y la libertad de Carlos Fonseca Amador
}

\author{
Homenaje al Comandante Fonseca Amador (1936-1976) \\ en ocasión del 80 aniversario de su nacimiento
}

\begin{abstract}
En junio de 1957 conocí en Moscú a Carlos Fonseca Amador, actual Secretario General del Frente Sandinista de Liberación Nacional de Nicaragua. Tenía entonces veintiún años de edad, estudiaba Leyes y se hacía llamar, por razones de seguridad, Pablo Cáceres*. Como yo y miles de jóvenes estudiantes de todo el mundo, había llegado hasta la Unión Soviética para participar en el VI Festival Mundial de la Juventud y los Estudiantes por la Paz y la Amistad.
\end{abstract}

Desde el principio hicimos muy buena amistad ya que a ambos nos atraían las discusiones políticas de tono $y$ duración ilimitados. Compartíamos el odio a la solemnidad y a la adustez, y creíamos en una Centroamérica unida a nivel popular. Fonseca ya militaba en el Partido Comunista**,
Se presenta un texto de gran valor histórico por su contenido y legado de solidaridad y hermandad que irradian, cada una de las líneas escritas por el salvadoreño Roque Dalton (1936-1975), uno de los más grandes intelectuales revolucionarios latinoamericanos del siglo XX. Escrito en ocasión de la campaña de solidaridad emprendida por intelectuales del mundo, como el mismo Dalton, Sartre, Beauvoir, a principios de 1970, quienes abogan por el respeto a la vida y la libertad del Secretario General del Frente Sandinista de Liberación Nacional (FSLN) Carlos Fonseca Amador, quien guardaba prisión en las cárceles de San José, Costa Rica, acusado por las autoridades de ese país de asalto a un banco.

Es un texto cuyo valor histórico radica en las revelaciones que hace el poeta revolucionario salvadoreño, acerca de la feliz coincidencia de conocer al Comandante Fonseca Amador durante el VI Festival mundial de la juventud y de los estudiantes por la paz y la amistad, celebrada en Moscú, Unión Soviética en el año de 1957. A partir de ese hecho, la amistad de Dalton y Fonseca Amador se consolida en la medida en que sabe de las hazañas y firmeza revolucionaria del líder nicaragüense.

Otro elemento interesante del texto, es el sentimiento de admiración y respeto hacia la personalidad del Comandante Fonseca Amador, reflejo de la humildad del gran poeta salvadoreño. Para esa época, Dalton ya era una figura reconocida y admirada internacionalmente por su entrega a la lucha revolucionaria y por sus escritos que circulaban entre los simpatizantes de la izquierda revolucionaria y sectores progresistas.

El encuentro de estos dos revolucionarios, por medio de este texto, es lo que ha motivado su publicación, como homenaje al 80 aniversario del nacimiento del Jefe de la Revolución Sandinista. Titulo imperecedero que resume su vida heroica e inclaudicable, y referente de un ideal al cual seguimos aferrados.

* Según Matilde Zinnmerman en el expediente que la Oficina de Seguridad Nacional (OSN) de la dictadura de Somoza había creado de Carlos Fonseca, se menciona que utilizó el seudónimo de Pablo Cáceres para viajar a los países, llamados en esa época, de la "Cortina de hierro".

** Existen muchas controversias en relación a la militancia para finales de la década del 50 del Comandante Fonseca Amador. Autores como Rafael Casanova Fuerte, sugieren una membresía en el Partido Socialista. De hecho existen evidencias documentales que el Comandante mantuvo comunicación estrecha con miembros del Partido Socialista y otras células marxista cercanas a UNAP (Unión Nacional de Acción Popular). Ver. Instituto de Estudios del Sandinismo (1985) Carlos: El eslabón vital. Cronología básica de Carlos Foseca Jefe de la Revolución 1936-1976. Managua: IES.; Casanova Fuertes, R. (2013) ; Zinnmerman, 
yo era aún un estudiante católico "en busca de la verdad", pero no hubo entre nosotros la menor diferencia de enfoque en lo que a Centroamérica se refería.

Recuerdo que en varias oportunidades evocamos la figura guerrillera de Sandino y la compleja historia de sus relaciones con el comunista salvadoreño Agustín Farabundo Martí, quien había sido su secretario particular en la montaña nicaragüense y en las giras latinoamericanas y que luego sería el principal dirigente de la insurrección campesina salvadoreña de 1932.

Recuerdo asimismo que participamos justos en casi todos los actos del Festival y, una vez terminado este, representamos a nuestros países en el IV Congreso de la Federación Mundial de Juventudes Democráticas en Kiev. En tierra soviética nos despedimos. Por la primera vez. No sabía yo entonces cuán entrañable iba a ser a partir de entonces para mí la figura de este amigo fugaz, presente siempre en noticias coladas desde la clandestinidad salvadoreña, y tuvimos algún contacto furtivo.

Para 1959 conocíamos de una decisión más alta aún que la simple militancia política en la que ya estábamos inmersos: Carlos Fonseca abandonó sus estudios universitarios y se incorporó a un movimiento guerrillero anti somocista que se organizaba entonces a partir de Honduras y que culminó con la acción conocida como la del Chaparral. En este combate, las fuerzas guerrilleras a las que pertenecía Carlos fueron cercadas por sorpresa, por fuerzas conjuntas de Honduras y Nicaragua y derrotadas.

A Fonseca Amador le atravesaron un pulmón de un balazo y ya lo dejaban por muerto, cuando al tratar uno de los soldados hondureños de despojarlo de sus botas, dio señales de vida. En un palenque improvisado lo sacaron de la zona en calidad de prisionero y lo llevaron a un hospital hondureño. Logró reponerse de sus graves heridas. Inmediatamente ingresó de nuevo a Nicaragua de manera clandestina.

En 1960 fue detectado y permaneció seis meses en prisión (desde donde logró hacer circular su enérgico panfleto Desde la cárcel yo acuso a la dictadura ${ }^{* * *}$, después de los cuales fue deportado hacia Guatemala, en nombre de la colaboración intergubernamental centroamericana. No era precisamente el exilio dorado lo que le esperaba en Guatemala: el gobierno guatemalteco lo hizo ubicar en el tenebroso campo de concentración de Poptún, en el centro de la selva de Petén, prácticamente a prueba de escapatoria ya que tiene un muro natural en derredor de cientos de kilómetros de selva impenetrable, poblada de fieras y reptiles.

Por una de esas paradojas de la historia, tan comunes en Centroamérica, en Poptún se encontraba entonces, castigado, como oficial de resguardo, el Teniente Luis Augusto Turcios Lima, quien llegaría ser el jefe máximo del movimiento guerrillero de Guatemala. Turcios recordaría siempre el valor que para él tuvo el contacto personal y la discusión con el revolucionario nicaragüense que para aquel entonces le superaba en los gajes del oficio guerrillero.

Las presiones de los sectores democráticos de Centroamérica hicieron que Fonseca Amador fuera finalmente liberado del campo de concentración y expulsado. Desde entonces lo encontramos de nuevo en Nicaragua al frente del movimiento armado

\footnotetext{
*** Este documento que el poeta Dalton menciona en realidad fue publicado en julio de 1964. La confusión, explicable, se debe al hecho que, tanto en 1960 a que hace referencia el poeta salvadoreño, como en el año 64, el Comandante Fonseca es apresado y en ambos casos, mediaron escritos importantes a la luz de su encarcelamiento. Es importante mencionar el escrito, leído en la Universidad Central de Venezuela, en marzo de 1960, titulado Breve análisis de la lucha popular nicaragüense contra la dictadura de Somoza.
} 
anti somocista, encabezando la organización que dirige la lucha revolucionaria del pueblo de Nicaragua contra la dictadura y el imperialismo: el Frente Sandinista de Liberación Nacional.

El FSLN fundado por Fonseca Amador se llamó inicialmente Movimiento de Liberación Nacional, y se denomina como ahora a partir de1962. Fonseca tuvo destacada participación en las acciones armadas llevadas a cabo por el Frente en la zona del río Bocay en 1963 y en la zona de Pancasán en 1967. A diez años de su participación como Pablo Cáceres en el Festival de Moscú, Carlos Fonseca Amador había entrado, para orgullo nuestro y de los revolucionarios centroamericanos, en la historia.

La tenacidad y el coraje excepcionales de Fonseca Amador no solamente se han puesto de relieve en las desiguales confrontaciones contra las fuerzas militares de la dictadura somocista. También ha sido un elemento central en la lucha indoblegable contra las concepciones oportunistas, reformistas y conciliadoras que han minado el campo de la revolución nicaragüense, manteniendo por encima de todas las vicisitudes, la adhesión en la práctica, a la línea central para la revolución de su país y de Centroamérica: la vía de la lucha armada, instrumentada a partir de las guerrillas rurales, en coordinación con las unidades tácticas urbanas.

El máximo dirigente del FSLN es una de las figuras más respetadas y queridas por las juventudes revolucionarias del istmo, que hoy se abocan a la gigantesca tarea de construir nuevas vanguardias para la lucha popular. En una zona minada por las maniobras del imperialismo que han desembocado incluso, en guerras fratricidas (como la de El Salvador y Honduras); en una zona en que el poder político se encuentra en manos de criminales tan abominables como Somoza en Nicaragua, Carlos Fonseca Amador representa la tradición combativa, el honor de los pueblos explotados y humillados.
Hace ya algunos meses, con ocasión de haber entrado de manera clandestina a Costa Rica por razones de trabajo anti somocista, Carlos fue capturado en San José y desde entonces guarda prisión, bajo la perenne amenaza de ser liquidado por la Agencia Central de Inteligencia de los Estados Unidos o por la dictadura somocista, cuyos agentes operan de manera abierta en territorio costarricense. Se le acusa de manera falsa de delitos comunes (asalto a un banco o complicidad en el mismo, tenencia de armas de guerra y explosivo, etc.)

En enero de este año [1970] un comando revolucionario intentó rescatar de la prisión al dirigente nicaragüense. En el transcurso de la acción un policía costarricense disparó contra los revolucionarios para impedir su rescate y estos se vieron obligados a responder el fuego, hiriendo mortalmente al policía. La policía de este país, alarmada por el tiroteo, pudo evitar la fuga de Fonseca, reduciéndolo nuevamente a la prisión en condiciones de extremo rigor. En estas condiciones, desde luego, el peligro para la vida del gran revolucionario nicaragüense se ha multiplicado. La muerte del policía fue aprovechada por el gobierno de Costa Rica para desacreditar al FSLN y a los grupos revolucionarios costarricenses, y para subrayar en la cabeza de las masas populares la supuesta excepcionalidad del país en el ámbito general de violencia centroamericana. Objetivamente, sin embargo, un hecho subsiste: el intento de rescate de Fonseca Amador por la vía violenta fue la respuesta de los revolucionarios centroamericanos al acto de violencia ejercido por el gobierno de Costa Rica al capturar y acusar de manera falsa al dirigente nicaragüense, acto de violencia que en la práctica responde a los intereses de la feroz dictadura de Somoza. La permanencia en prisión de Fonseca Amador en Costa Rica sigue apareciendo a los ojos de todas las personas progresistas de Costa Rica, Centroamérica y el mundo, como un acto de complicidad de las autoridades costarricense con la incalificable satrapía 
que oprime, desde hace años al pueblo de Nicaragua, sobre la base de un permanente baño de sangre popular.

Un signo de este sentimiento general ha sido el mensaje de los intelectuales franceses encabezados por Jean Paul Sartre y Simone de Beavoir en el que se pide al gobierno de Costa Rica las garantías necesarias para la vida de Fonseca y su inmediata libertad.

Entre las masas populares costarricenses, el odio hacia la dictadura de Somoza es evidente. El pueblo costarricense recuerda que su territorio nacional nunca ha sido considerado "soberano", "neutral", etc., por el somocismo, que ha propiciado incluso invasiones armadas contra Costa Rica. De ahí que, incluso contra la amplia campaña desatada en los medios publicitarios destinada a tergiversar la lucha del FSLN y a darle un aspecto negativo a las incidencias surgidas del intento de rescate, el sentimiento del pueblo costarricense sigue siendo solidario con el patriota nicaragüense detenido de manera arbitraria y exige su libertad en nombre de las tradiciones nacionales y del respeto a los principios de solidaridad con los luchadores democráticos y revolucionarios de Centroamérica.
En estos momentos, un nuevo gobierno está a punto de subir al poder en Costa Rica enarbolando la bandera de la "lucha contra la miseria", las "reformas estructurales, el "beneficio popular". Surgido de las urnas electorales, pretenderá hacer de Costa Rica, según las expresiones del Presidente

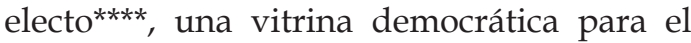
mundo. El caso de Carlos Fonseca Amador será desde el principio, lo es desde ahora, definitorio del nuevo régimen. No hay vitrina democrática que soporte ninguna forma de solidaridad con el gobierno de Somoza. Ni habrá política mágica que evite a las masas costarricenses tomar partido frente al desarrollo de la lucha revolucionaria de Centroamérica.

Por ello, se impone en estos momentos un redoblamiento de la campaña internacional de solidaridad con Carlos Fonseca Amador, en exigencia de su libertad. No en petición suplicante de una libertad estéril: en reclamo de una libertad que le permita a Fonseca Amador, volver a ejercer su responsabilidades revolucionarias en Nicaragua, en la lucha frontal contra una de las dictaduras que más llena de vergüenza la historia de América Latina.

**** Al Presidente que hace referencia Roque Dalton es a José Figueres Ferrer, quien ganara las elecciones del año de 1970, asumiendo un tercer mandato presidencial. 